\title{
A assistência da enfermeira após perda perinatal: o luto após o parto
}

\author{
Nurse assistance after perinatal loss: grief after child birth \\ Asistencia de enfermería después de la pérdida perinatal: pena después del parto
}

Mariana Lopes Teixeira ORCID: https://orcid.org/0000-0002-1382-3271

Universidade Estácio de Sá, Brasil

E-mail: marianalopestx@gmail.com

Larissa Bastos Viegas

ORCID: https://orcid.org/0000-0002-0828-8083

Universidade Estácio de Sá, Brasil

E-mail: larissa.lv98@hotmail.com

Larissa Lessa dos Santos

ORCID: https://orcid.org/0000-0002-8947-6691

Universidade Estácio de Sá, Brasil

E-mail: larissalessaa@hotmail.com

Raisa Silva dos Santos

ORCID: https://orcid.org/0000-0002-1716-8796

Universidade Estácio de Sá, Brasil

E-mail: silvaaissar@gmail.com

Priscilla Duarte Soares Correa

ORCID: https://orcid.org/0000-0002-9227-1259

Universidade Estácio de Sá, Brasil

E-mail:priscillakdsoares@yahoo.com.br

Paula de Carvalho Pereira Pitombeira

ORCID: https://orcid.org/0000-0002-7316-0713

Universidade Federal do Estado do Rio de Janeiro, Brasil

E-mail: paulapitombeira.pp@gmail.com

Elziane Alves Ribeiro

ORCID: https://orcid.org/0000-0001-5366-2460

Universidade Estácio de Sá, Brasil

E-mail:elzialvesribeiro@gmail.com

Jéssica Silva de Santana

ORCID: https://orcid.org/0000-0002-3470-778X

Universidade Estácio de Sá, Brasil

E-mail: jsantanaa.estacio@gmail.com

Bárbara Cristina Fulgencio Vieira

ORCID: https://orcid.org/0000-0001-7006-1448

Universidade do Grande Rio Professor José de Souza Herdy, Brasil

E-mail: cristina_barbara18@hotmail.com

Vanessa Vianna da Silva Barbosa

ORCID: https://orcid.org/0000-0002-6093-0774

Universidade Estácio de Sá, Brasil

E-mail: vanessa_vianna@outlook.com.br

Raiane de Carvalho Machado Oliveira

ORCID: https://orcid.org/0000-0003-1971-1307

Universidade Estácio de Sá, Brasil

E-mail: raiane_live@hotmail.com

Renata Brito de Sousa Magalhães

ORCID: https://orcid.org/0000-0002-7536-5034

Universidade Estácio de Sá, Brasil E-mail: renatabds17@gmail.com

Patrícia de Camargo

ORCID: https://orcid.org/0000-0002-6161-356X

Universidade Estácio de Sá, Brasil

E-mail: patycamargo1011@gmail.com

Priscila de Almeida Cunha Silva

ORCID: https://orcid.org/0000-0002-2322-634X

Universidade Estácio de Sá, Brasil

E-mail: priscilaalmeida_c@yahoo.com.br

João Pedro Nunes Pereira de Oliveira

ORCID: https://orcid.org/0000-0001-7235-8018

Universidade Estácio de Sá, Brasil

E-mail: joaopnpo@outlook.com 


\author{
Alissane de Oliveira Torres \\ ORCID: https://orcid.org/0000-0001-5649-1740 \\ Universidade Estácio de Sá, Brasil \\ E-mail: alissane.oliver@gmail.com \\ Jorge Gabriel Maia Soares \\ ORCID: https://orcid.org/0000-0001-9601-5095 \\ Universidade Estácio de Sá, Brasil \\ E-mail: jgms2000@gmail.com \\ Layna Pereira de Amorim \\ ORCID: https://orcid.org/0000-0002-9825-8848 \\ Universidade Estácio de Sá, Brasil \\ E-mail: amorimlayna@hotmail.com \\ Caroline da Costa Pereira \\ ORCID: https://orcid.org/0000-0002-1496-587X \\ Universidade Estácio de Sá, Brasil \\ E-mail: karol.hatha@gmail.com \\ Brenda Giovanna Rufino Ferreira de Almeida \\ ORCID: https://orcid.org/0000-0002-5665-7541 \\ Universidade Estácio de Sá, Brasil \\ E-mail: brendagiovanna@ hotmail.com
}

\title{
Resumo
}

Introdução: A morte independente da ocasião leva a sensação de luto. No que se refere ao óbito de um bebê esse processo altera a lei orgânica da vida, bem como impossibilita os propósitos, as expectativas, as promessas que normalmente são depositados ao bebê que está para chegar. Objetivo: Identificar através do estudo da arte as dificuldades enfrentadas pelas famílias diante da perda perinatal e descrever a importância da enfermagem no cuidado das famílias enlutadas. Metodologia: Trata-se de um estudo com abordagem qualitativa, do tipo revisão integrativa, que teve como base de dados a Biblioteca Virtual de Saúde Enfermagem usando os Descritores em Ciências da Saúde (DeCS): Luto; Perinatal; Família; Enfermagem. Foram selecionados artigos completos, em língua portuguesa e inglesa publicados entre 2010 a 2020. Ao fim da aplicação dos critérios, emergiram 6 artigos para leitura minuciosa e construção do conteúdo. Resultados: Na análise de dados foram estabelecidas duas categorias: Categoria I - Famílias Enlutadas e Categoria II A enfermeira frente à situação de luto perinatal. Considerações Finais: Conclui-se que o processo de luto é vivenciado por cada indivíduo de forma diferente e é importante saber respeitar a particularidade de cada um. É importante identificar precocemente sinais de alerta como estresse pós-traumático, ansiedade, depressão que podem influenciar negativamente em uma futura gestação, assim como em problemas no casamento.

Palavras-chave: Luto; Perinatal; Família; Enfermagem.

\begin{abstract}
Introduction: Death regardless of the occasion leads to a feeling of mourning. With regard to the death of a baby, this process alters the organic law of life, as well as precluding the purposes, expectations, promises that are normally placed on the baby that is about to arrive. Objective: To identify through the study of art the difficulties faced by families in the face of perinatal loss and describe the importance of nursing in the care of bereaved families. Methodology: This is a study with a qualitative approach, of the integrative review type, whose database was the Virtual Health Library Nursing using the Health Sciences Descriptors (DeCS): Mourning; Perinatal; Family; Nursing. Complete articles were selected, in Portuguese and English, published between 2010 and 2020. At the end of the application of the criteria, 6 articles emerged for thorough reading and construction of the content. Results: In the data analysis, two categories were established: Category I - Bereaved Families and Category II - The nurse in the face of perinatal mourning. Final Considerations: It is concluded that the grieving process is experienced by each individual differently and it is important to know how to respect the particularity of each one. It is important to identify early warning signs such as post-traumatic stress, anxiety, depression that can negatively influence a future pregnancy, as well as problems in the marriage.
\end{abstract}

Keywords: Mourning; Perinatal; Family; Nursing.

\section{Resumen}

Introducción: la muerte, independientemente de la ocasión, conduce a una sensación de luto. Con respecto a la muerte de un bebé, este proceso altera la ley orgánica de la vida, además de excluir los propósitos, expectativas y promesas que normalmente se le imponen al bebé que está por llegar. Objetivo: Identificar a través del estudio del arte las dificultades que enfrentan las familias ante la pérdida perinatal y describir la importancia de la enfermería en el cuidado de las familias desconsoladas. Metodología: Este es un estudio con un enfoque cualitativo, del tipo de revisión integradora, cuya base de datos era la Enfermería de la Biblioteca Virtual en Salud utilizando los Descriptores de Ciencias de la Salud (DeCS): Duelo; Perinatal; Familia; Enfermería. Se seleccionaron artículos completos en portugués e inglés publicados entre 2010 y 2020. Al final de la aplicación de los criterios, surgieron 6 artículos para una lectura exhaustiva y la construcción del contenido. Resultados: En el análisis de los datos, se establecieron dos categorías: Categoría I Familias desconsoladas y Categoría II - La enfermera ante el duelo perinatal. Consideraciones finales: Se concluye que el proceso de duelo es experimentado por cada individuo de manera diferente y es importante saber cómo respetar la 
particularidad de cada uno. Es importante identificar las primeras señales de advertencia, como el estrés postraumático, la ansiedad, la depresión que pueden influir negativamente en un futuro embarazo, así como los problemas en el matrimonio.

Palabras clave: Duelo; Perinatal; Familia; Enfermería.

\section{Introdução}

O desfecho de uma perda gestacional nem sempre foi valorizado como nos dias atuais. Antigamente, no período da Idade Média, o óbito fetal era visto como algo indiferente para a população. Os bebês não eram tão apreciados como são hoje em dia. Podemos levar em consideração algumas diferenças de comportamento, como: muitas crianças não eram registradas e não tinham nome naquela época. A partir do século XIX em diante que as crianças começaram a ter seu valor na sociedade. Santos et al. (2012)

Desde então, a imagem da maternidade, culturalmente dizendo, é amplamente conhecida como sinônimo de sucesso. O nascimento de um filho é considerado um acontecimento feliz para as famílias, mas, infelizmente, algumas gravidezes terminam em perda. Monteiro et al. (2011).

Com a evolução da tecnologia houve uma redução do número de mortes fetais, uma vez que esta permitiu uma visualização por menorizada e rastreio antecipado de complicações durante a gravidez e parto. Monteiro et al. (2012).

No entanto, apesar de cada vez mais raras, estas situações continuam a acontecer, envolvendo um quadro de dor e drama que dificulta a atuação dos profissionais de saúde que não se sentem preparados para lidar com a morte num ambiente em que diariamente surgem novas vidas. Monteiro et al. (2012).

Os genitores normalmente enfrentam a gestação tardia e o falecimento do filho como um episódio extremamente doloroso e intensamente traumático. Nos últimos anos, estudos identificaram que o óbito perinatal ou de um recém-nascido pode provocar enlutamento duradouro ou dificultoso para muitos progenitores. Gold (2007).

Assim, o óbito precoce de um bebê anterior ou posteriormente ao nascer acaba com a lei orgânica da vida, bem como impossibilita os propósitos, as expectativas, as promessas que habitualmente são entregues ao bebê que está para chegar. Muza et al. (2013).

O problema de concepção do sofrimento resultante da morte de um feto ou de um bebê que acabou de nascer é autodenominado por Iaconelli (2007) como luto perinatal, que é a temática relatada neste estudo, sendo esta rejeitada pela comunidade. Prefere-se a recusa, evitando chegar próximo da aflição. Desta forma, as atitudes dos indivíduos frente à exposição do óbito de um bebê são vivenciadas e analisadas pelos genitores de forma perturbadora. Muzaet al. (2013).

A morte seja de qual for à ordem ocasiona sensação de luto. O luto é definido como um comportamento natural e é previsto quando o laço é quebrado, e seu papel é garantir a restauração de soluções e possibilitar uma maneira de acomodação às alterações sucedidas em resultado das perdas. Alguns autores evidenciam que existem algumas condições que provocam o episódio do luto: causas internas, organização psicológica do indivíduo que está de luto, perdas prévias, contexto do óbito, convicções de caráter cultural ou religioso e o suporte ganho. Muza et al. (2013).

Cada indivíduo encara essa fase de uma forma. O luto deve ser entendido como um processo individualizado. As manifestações dependerão do vínculo que existia com a pessoa que perderam. Ainda hoje a sociedade possui dificuldade de abordar a temática por ser uma reflexão delicada e que envolve muitos sentimentos. (Gonçalves \& Bittar, 2016).

O luto é um processo doloroso em todas as situações, seja em maior ou menor proporção. Estudos apontam que algumas pessoas podem demorar um certo tempo para elaborar esse momento, isso vai depender da individualidade de cada um. Não é possível seguir uma regra de como a pessoa irá se comportar ou sentir. (Bimbatti César, Nogueira, Miranda \& Rolim, 2015) 
Muitas pessoas fazem comentários desagradáveis como " isso vai passar “, " vocês são novos e podem tentar de novo ", frases como essas desmerecem o sofrimento de quem está passando pelo luto, sendo inclusive gatilho para desenvolvimento de transtornos psicológicos dos pais e familiares. (Aguiar \& Zorning, 2016)

Os profissionais de saúde estão envolvidos diretamente na assistência à família enlutada, acolhendo, auxiliando os pais a se despedir de seu filho e orientando sobre o procedimento do luto. Pesquisas apontam que o profissional que fornece cuidado pode fazer os familiares se sentirem mais acolhidas e amparadas após a perda de seu filho. Gold (2007).

A Enfermagem é uma profissão que lida com o ser humano, interage com ele e requer o conhecimento de sua natureza física, social e psicológica. Desta forma, o cuidar pode ser caracterizado pela atenção, zelo e preocupação com o outro. Aguiar et al. (2006).

O cuidar está inserido desde o nascer até o morrer. A finalidade desta ação implica aliviar, ajudar, pois a cura não é o fim, devendo estar presente até mesmo no processo de morrer. Aguiar et al. (2006).

É de extrema relevância que a enfermeira observe os sinais e sintomas mais comuns que a mulher possa desencadear nesse período, como: frutração pela perda, decepção, revolta, tristeza, culpa por ter sido incapaz de fazer algo para modificar a situação, choro e em casos mais complexos, a depressão. Santos et al. (2012)

É preciso ter uma escuta ativa dos familiares, pois pesquisas comprovam que evitar falar sobre a situação tende a desfechos negativos. Dessa forma, os profissionais conseguem detectar angústias, medos e sentimentos que os mesmos venham a sentir, podendo elaborar estratégias para auxiliar. É possível realizar encaminhamento para outro profissional, como psicólogo e assistente social. Santos et al. (2012)

No que diz respeito à rede de apoio, pode ser mais complexo definir uma assistência emocional aos genitores, pois a característica deste falecimento torna-se difícil para o entendimento e aceitação por alguém que não passou por uma situação parecida. Esse cenário impossibilita a constatação e preparação do luto pelos familiares. É comum que alguns profissionais priorizem a assistência física, distanciando-se das emoções com a intenção de reduzir sua aflição.

Habitualmente, colocam em ação métodos, posicionamentos e atos distintos. Desta forma, em diversas situações, seu desempenho é inadequado, respondem de longe, quase que friamente, e omitem a importância do falecimento, especialmente no início de gravidez. Comprova-se a carência de técnicas, ferramentas e de planejamento para encarar esses episódios e dar feedbacks às necessidades desses pais.

A ocorrência do falecimento de bebês, a mudez, habitual por parcelados indivíduos que se encontram à volta dos familiares enlutados, pode dar a sentido de que esse não é tem significado, pois o feto não foi introduzido na sociedade. Deste modo, essa morte passa como imperceptível, assim os profissionais de saúde precisam ficar alerta, para não reproduzir esse comportamento. Desse ponto a relevância dos sistemas de saúde ofertar um auxílio sensível aos pais que perderam seus filhos de forma precoce, lidando com informação do óbito e de oferecendo suporte. Pereira et al. (2018).

Por essas considerações, faz-se necessário o conhecimento das dificuldades enfrentadas pelas famílias diante da perda perinatal assim como a assistência prestada as famílias enlutadas de modo a pensar em estabelecer as melhores estratégias assistenciais buscando melhorar a qualidade dos cuidados prestados.

É de extrema importância que o profissional informe aos pais sobre o direito da licença maternidade remunerada mesmo após o falecimento do recém-nascido, o que auxilia no processo de luto ficando perto de sua rede de apoio no maior tempo possível, já que a mulher estará acolhida legalmente, tendo seu emprego garantido quando finalizar o prazo estipulado por lei. CLT, Art. 396 (2016)

Nesta perspectiva, a questão que subsidiou a pesquisa foi: Qual as dificuldades enfrentadas pelas famílias diante da perda perinatal? Assim, o presente estudo apresenta como objeto "as dificuldades enfrentadas pelas famílias diante da perda perinatal". 
Foram traçados os seguintes objetivos:

- Identificar através do estudo da arte as dificuldades enfrentadas pelas famílias diante da perda perinatal e descrever a importância da enfermagem no cuidado das famílias enlutadas.

\subsection{Justificativa}

O estudo se justifica a partir da dificuldade dos profissionais de saúde em encarar o óbito perinatal ou neonatal e aos obstáculos enfrentados pelos pela sociedade para enfrentar esse tipo de luto precoce. A partir do exposto fica clara a importância da elaboração de uma revisão de literatura destacando o tema.

\subsection{Relevância}

A relevância para os acadêmicos de enfermagem se faz com a intenção de informar e buscar uma reflexão sobre a temática, uma vez que será de grande importância para a assistência realizada por eles no futuro; social por levar à sociedade o conhecimento científico ao qual, de costume, ela não teria acesso, e para fins de pesquisa, já que outros poderão então fazer uso dos dados encontrados e aqui reunidos e analisados. A temática escolhida vem ganhando grande proporção no interior da própria universidade e dos seus centros de pesquisa, sendo assim, o estudo torna-se indispensável para acadêmicos, pesquisadores e sociedade.

\section{Metodologia}

Trata-se de um estudo de abordagem qualitativa, do tipo revisão integrativa no qual consta no procedimento de seis etapas que são a identificação do tema e seleção da hipótese, estabelecimento da estratégia de pesquisa, definição e coleta de dados, análise dos dados coletados, interpretação e apresentação dos resultados, onde será abordado o óbito perinatal após o parto. A revisão do processo baseou-se nas recomendaçõe da lista de conferência Preferred Reporting Items for Systematic Reviews and Meta-Analyses (PRISMA).

De acordo com Severino (2016) ao ingressar no sistema de ensino superior se torna indispensável o planejamento e práticas de trabalhos de pesquisas e extensão. Efetivamente, as iniciações científicas poderiam ser executadas por todo corpo social com intuito de se organizar para as novas técnicas e modificações que acontecem no decorrer dos anos. Pereira A.S. et al. (2018).

A metodologia é o trajeto para se elaborar algo quando se tem a direção, é mais fácil efetuar viagens compreendendo em que lugar se está e para onde quer ir e como fazer. Segundo Estrela (2005) ao produzir conteúdos de trabalhos de metodológicos para área de saúde, julga que os casos podem ser trabalhados através da metodologia qualitativa e quantitativa. Pereira et al. (2018).

As metodologias qualitativas são aquelas em que é relevante o esclarecimento por parte dos autores com seus pontos de vista sobre a temática em questão. Nestes, na maioria das vezes, os dados são recolhidos através de reuniões com conteúdos abertos. Pereira et al. (2018).

A estratégia de identificação e seleção dos artigos originou-se através da busca da Biblioteca Virtual de Saúde (BVS), com acesso as seguintes bases de dados eletrônicas como a Literatura Latino-Americana e do Caribe em Ciências da Saúde (LILACS), Medical Literature Analysis and Retrieval System Online (MEDLINE), Banco de Dados em Enfermagem (BDENF) e Scientific Electronic Library Online - Biblioteca Científica Eletrônica em Linha (SCIELO). Foram, também, realizadas buscas manuais nas listas de referências dos artigos selecionados no mês de junho de 2020. Foram utilizados os seguintes descritores em ciências da saúde (DeCS): Luto; Perinatal; Família; Enfermagem e com o uso do boleador “and”. Foram adotados os seguintes critérios de inclusão para seleção dos artigos: materiais completos, em português e inglês, no formato de artigo e com recorte 
temporal de 2010 a 2020. Os critérios de exclusão foram os artigos duplicados, incompletos e que não atendiam a temática do estudo.

Os artigos selecionados foram tabelados individualmente, por título, autores, ano de publicação, periódico, objetivos, métodos, nível de evidência e considerações finais. A partir de então iniciou a análise bibliométrica destes que foram agrupados por similaridade sob forma de categorias. Os artigos foram classificados quanto ao nível de evidência. Nesta revisão, foi empregado o sistema de classificação composto de sete níveis, sendo: nível I - evidências oriundas de revisões sistemáticas ou metanálise de relevantes ensaios clínicos; nível II - evidências derivadas de pelo menos um ensaio clínico randomizado controlado bem delineado; nível III - ensaios clínicos bem delineados, sem randomização; nível IV - estudo de coorte e de casocontrole bem delineados; nível V - revisão sistemática de estudos descritivos e qualitativos; nível VI - evidências derivadas de um único estudo descritivo ou qualitativo; e nível VII - opinião de autoridades ou relatório de comitês de especialistas (Melnyk., Fineout-Overholt, 2011).

Figura 1: Segue abaixo o fluxograma com a seleção dos artigos para a Revisão Integrativa.

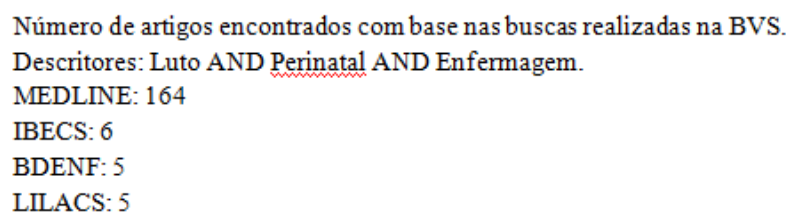

Número de estudos publicados nos últimos 10 anos (2010-2020), textos íntegros, em língua portuguesa e inglesa:

MEDLINE: 42

BDENF: 3

LILACS: 3

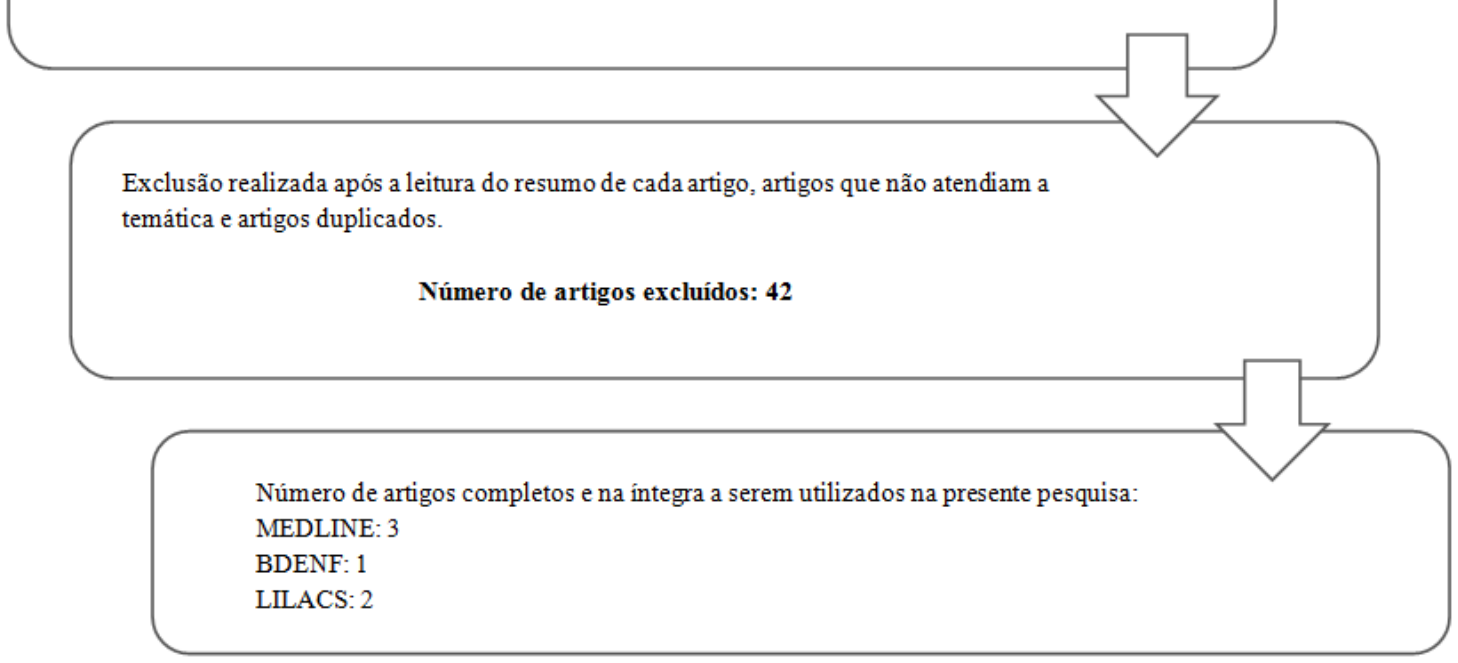

Fonte: Biblioteca Virtual de Saúde

Com base no fluxograma exposto acima, nota-se que os autores selecionaram o total de 06 artigos de acordo com os critérios de inclusão e exclusão para leitura minuciosa e elaboração da pesquisa. 


\section{Resultados e Discussão}

Assim, emergiram 06 artigos nas bases de dados pesquisadas através das estratégias de busca (Figura 1) com os critérios citados anteriormente, os quais se procederam à leitura minuciosa para a construção do conteúdo, destacando aqueles que responderam ao objetivo proposto pelo estudo, com intuito de organizar os dados de acordo com o objetivo proposto. Os resultados apresentados no estudo mostram a dificuldade dos familiares e profissionais em lidar com o óbito perinatal e deixa clara a importância da criação de medidas que auxiliem no enfrentamento dessa situação.

Quadro 1: Características dos artigos analisados no período de 2010 a 2020

\begin{tabular}{|l|c|c|c|c|c|l|}
\hline \multicolumn{1}{|c|}{ Título } & Autoria & $\begin{array}{c}\text { Base de } \\
\text { dados }\end{array}$ & ANO & Objetivo & $\begin{array}{l}\text { Métodos/Nivel } \\
\text { de Evidência }\end{array}$ & $\begin{array}{c}\text { Considerações } \\
\text { Finais }\end{array}$ \\
\hline $\begin{array}{l}\text { O cuidado à } \\
\text { família diante da } \\
\text { perda neonatal: } \\
\text { uma reflexão } \\
\text { sob a ótica da } \\
\text { teoria da } \\
\text { complexidade }\end{array}$ & $\begin{array}{l}\text { Ichikawa, } \\
\text { Sampaio, } \\
\text { Sá, Szylit, } \\
\text { Santos e } \\
\text { Vargas. }\end{array}$ & BDENF & 2017 & $\begin{array}{l}\text { Retratar o cuidado } \\
\text { voltado para a família } \\
\text { que passou pelo óbito } \\
\text { neonatal. }\end{array}$ & $\begin{array}{c}\text { Estudo } \\
\text { qualitativo }\end{array}$ & $\begin{array}{l}\text { O estudo visa } \\
\text { ajudar a entender } \\
\text { o processo de } \\
\text { luto que é difícil } \\
\text { para os } \\
\text { familiares, } \\
\text { assim, } \\
\text { aprimorando } \\
\text { ações a serem } \\
\text { realizadas pelos } \\
\text { profissionais de } \\
\text { saúde para o } \\
\text { cuidado às } \\
\text { famílias. }\end{array}$ \\
\hline
\end{tabular}

\begin{tabular}{|l|l|c|c|l|c|l|}
\hline $\begin{array}{l}\text { Fatores } \\
\text { associados ao } \\
\text { estado de luto } \\
\text { após óbito fetal: } \\
\text { estudo } \\
\text { comparativo } \\
\text { entre brasileiras } \\
\text { e canadenses }\end{array}$ & $\begin{array}{c}\text { Paris, } \\
\text { Montigny e } \\
\text { Pelloso. }\end{array}$ & LILACS & 2016 & $\begin{array}{l}\text { Analisar a } \\
\text { comparação entre o } \\
\text { luto complicados e os } \\
\text { aspectos } \\
\text { sociodemográficos, } \\
\text { reprodutivos, mentais, } \\
\text { de bem-estar conjugal } \\
\text { e auxilio profissional } \\
\text { em mulheres que } \\
\text { viveram o óbito } \\
\text { perinatal. }\end{array}$ & $\begin{array}{c}\text { Estudo } \\
\text { transversal }\end{array}$ & $\begin{array}{l}\text { Nota-se que } \\
\text { mulheres } \\
\text { brasileiras, com } \\
\text { baixa } \\
\text { escolaridade, que } \\
\text { nível V } \\
\text { napo têm um } \\
\text { apoio } \\
\text { profissional, não } \\
\text { estão felizes com } \\
\text { seus parceiros e } \\
\text { não possuem } \\
\text { vínculo com a } \\
\text { religião, são as } \\
\text { que mais } \\
\text { precisam ser } \\
\text { analisadas. }\end{array}$ \\
\hline
\end{tabular}




\begin{tabular}{|c|c|c|c|c|c|c|}
\hline $\begin{array}{l}\text { Adaptação } \\
\text { transcultural e } \\
\text { evidências de } \\
\text { validação da } \\
\text { Perinatal grief } \\
\text { scale1 }\end{array}$ & $\begin{array}{c}\text { Paris, } \\
\text { Montigny e } \\
\text { Pelloso. }\end{array}$ & LILACS & 2017 & $\begin{array}{l}\text { Realizar a adaptação } \\
\text { transcultural e } \\
\text { evidências de } \\
\text { validação } \\
\text { da Perinatal } \\
\text { GriefŚcale para } \\
\text { português do Brasil e } \\
\text { francês do Canadá. }\end{array}$ & $\begin{array}{l}\text { Estudo } \\
\text { descritivo } \\
\quad \quad- \\
\text { Evidência } \\
\text { nível V }\end{array}$ & $\begin{array}{l}\text { A Perinatal } \\
\text { GriefScale pode } \\
\text { ser utilizada para } \\
\text { identificação do } \\
\text { estado de luto } \\
\text { em mulheres que } \\
\text { tiveram óbito } \\
\text { fetal, na } \\
\text { respectiva versão } \\
\text { de cada país. }\end{array}$ \\
\hline $\begin{array}{l}\text { Cuidando do } \\
\text { neonato que está } \\
\text { morrendo e sua } \\
\text { familia: } \\
\text { vivências do } \\
\text { enfermeiro de } \\
\text { terapia intensiva } \\
\text { neonatal }\end{array}$ & $\begin{array}{c}\text { Almeida, } \\
\text { Moraes e } \\
\text { Cunha. }\end{array}$ & MEDLINE & 2016 & $\begin{array}{l}\text { Apreender sobre as } \\
\text { práticas vivenciadas } \\
\text { por enfermeiros na } \\
\text { UTIN, atuando no } \\
\text { cuidado e auxilio aos } \\
\text { neonatos em fase } \\
\text { terminal e seus } \\
\text { familiares, e observar } \\
\text { seus pensamentos } \\
\text { acerca de suas ações } \\
\text { no processo de óbito e } \\
\text { luto. }\end{array}$ & $\begin{array}{c}\begin{array}{c}\text { Estudo } \\
\text { descritivo }\end{array} \\
\quad- \\
\text { Evidencia } \\
\text { nivel V }\end{array}$ & $\begin{array}{l}\text { Para os } \\
\text { enfermeiros da } \\
\text { UTIN, passar } \\
\text { pelo processo de } \\
\text { morte e luto faz } \\
\text { com que eles } \\
\text { repercutam isso } \\
\text { na própria vida, } \\
\text { tormando-o mais } \\
\text { dificultoso. } \\
\text { Saber lidar com } \\
\text { esse momento é } \\
\text { um grande } \\
\text { obstáculo para } \\
\text { eles. }\end{array}$ \\
\hline $\begin{array}{l}\text { Melhores } \\
\text { práticas para } \\
\text { cuidados } \\
\text { paliativos } \\
\text { perinatais }\end{array}$ & $\begin{array}{c}\text { Ryan, } \\
\text { Bemhard, } \\
\text { Fahlberg. }\end{array}$ & MEDLINE & 2015 & $\begin{array}{l}\text { Ressaltar algumas } \\
\text { práticas a serem } \\
\text { realizadas para } \\
\text { formecer conforto para } \\
\text { o final da vida de um } \\
\text { neonato, assim como } \\
\text { auxiliar a familia } \\
\text { durante todo o } \\
\text { processo. }\end{array}$ & $\begin{array}{c}\text { Guia de } \\
\text { prática clínica } \\
- \\
\text { Evidência } \\
\text { nível V }\end{array}$ & $\begin{array}{l}\text { Guia prático } \\
\text { importante para } \\
\text { que o enfermeiro } \\
\text { saiba lidar da } \\
\text { melhor forma } \\
\text { com esse } \\
\text { processo. }\end{array}$ \\
\hline $\begin{array}{l}\text { Intensidade do } \\
\text { luto, bem-estar } \\
\text { psicológico e } \\
\text { relacionamento } \\
\text { intimo com }\end{array}$ & $\begin{array}{c}\text { Hutti, } \\
\text { Armstrong, } \\
\text { Myers e } \\
\text { Hall. }\end{array}$ & MEDLINE & 2015 & $\begin{array}{l}\text { Avaliar a durabilidade } \\
\text { da Escala de } \\
\text { Intensidade de Luto } \\
\text { Perinatal (PGIS) e a } \\
\text { sua relação com a }\end{array}$ & $\begin{array}{c}\text { Estudo } \\
\text { transversal } \\
-\end{array}$ & $\begin{array}{l}\text { Observou-se que } \\
\text { o PGIS } \\
\text { demonstrou } \\
\text { relações } \\
\text { significativas no }\end{array}$ \\
\hline
\end{tabular}




\begin{tabular}{|l|l|l|l|l|}
\hline $\begin{array}{l}\text { parceiros na } \\
\text { gravidez } \\
\text { subsequente } \\
\text { após uma perda } \\
\text { perinatal }\end{array}$ & & $\begin{array}{l}\text { força do luto com o } \\
\text { bem-estar psicológico } \\
\text { e a capacidade das } \\
\text { relações interpessoais } \\
\text { entre as mulheres e } \\
\text { seus parceiros na } \\
\text { gravidez futura após o } \\
\text { óbito perinatal Os } \\
\text { efeitos do luto após } \\
\text { essa perda podem } \\
\text { trazer muitos } \\
\text { problemas tanto } \\
\text { psicológicos, quanto } \\
\text { na vida do casal. }\end{array}$ & $\begin{array}{l}\text { Evidência } \\
\text { nível V }\end{array}$ & $\begin{array}{l}\text { que já era } \\
\text { esperado, como } \\
\text { alterações } \\
\text { psicológicas e } \\
\text { problemas } \\
\text { conjugais. A } \\
\text { escala é uma boa } \\
\text { opção para os } \\
\text { profissionais, } \\
\text { pois pode } \\
\text { auxiliar na } \\
\text { identificação de } \\
\text { mulheres que } \\
\text { precisam de } \\
\text { ajuda após a } \\
\text { perda. }\end{array}$ \\
\hline
\end{tabular}

Fonte: Autores

No quadro acima, os autores reuniram os artigos escolhidos para evidenciar as principais informações de cada pesquisa, como: objetivo, metodologia, nível de evidência e considerações finais. Com isso, foi possível notar pontos em comum e divergentes, tendo informações mais diretas e precisas que os auxiliaram no decorrer da elaboração deste trabalho.

Após essas análises, foram construídas as seguintes categorias, de acordo com as dificuldades encontradas pelas famílias no enfrentamento do luto perinatal.

\section{Categoria I - Famílias Enlutadas}

O luto é resultado da vivência do término e ocorre quando na vida, há a perda de algo ou alguém. Neste momento, inicia-se um grande sofrimento emocional por parte da pessoa que sofreu tal perda, esse processo é único e cada pessoa passa por ele de formas diferentes. O luto traz ao enlutado novas concepções, assim como uma nova estruturação de sua própria identidade frente a perda de seu ente, ele requer certo tempo para que se acostume e de certa forma aceite o acontecimento. (Ichikawa et al., 2017).

Diante desse contexto, podemos abordar o luto pela morte de um filho, assim, fala-se do óbito perinatal, que inclui a morte neonatal, aborto espontâneo e natimorto. Alguns estudos mostraram que mulheres que vivenciaram esse tipo de perda, tinham maiores possibilidades em desenvolver estresse pós-traumático, ansiedade, depressão, e que possivelmente isso influenciaria negativamente em uma futura gestação, assim como em problemas no casamento. (Alli et al., 2015).

No casamento, alguns casais encontram dificuldades para lidar com a perda juntos, visto que para alguns parceiros há uma forma diferente de agir e saber se portar neste momento, não sabendo até mesmo qual o tempo necessário para sofrer após o óbito perinatal, assim, de certa forma não ocorre o real apoio necessário. (Hutti et al., 2015).

Perder um filho pode ser considerado um dos acontecimentos mais arrasadores, ele envolve três momentos diferentes, são eles: o passado onde houve a idealização do sonho, a desilusão e a tristeza que parecem ser infinitos pelo presente momento e a dúvida sobre o futuro. (Almeida et al., 2016).

O luto envolve toda a família e não só os pais, quando há a morte no início da vida, o impacto causado na vida de todos, é muito grande. No momento da perda perinatal, pode acontecer tanto a construção quanto a desconstrução dessa família, ocorrendo transformações constantes e próprias das fases da vida em que a família está passando. (Ichikawa et al., 2017). 
Quando há a morte na fase perinatal, para a família aceitar esse fato é muito mais complicado, pois por se tratar de um natimorto ou neonato que falece após algumas horas de vida, isso pode parecer uma lástima muito maior, visto que todos criaram expectativas no decorrer da gravidez para o nascimento da criança na sua forma mais perfeita, e ao final, ao invés disso, se deparam com um óbito. Desta forma, com o passar do tempo é necessário que concluam os vínculos com o bebê, para que se desliguem dele e consigam focar nas necessidades que de fato a família precisa nesse momento da vida, para que haja uma evolução no processo de luto. (Almeida et al., 2016).

Como foi falado anteriormente, todo o processo de morte ocorre de forma intensa e atinge de forma geral a todos da família, sendo assim, é necessário que haja técnicas de comunicação eficazes e escuta terapêutica, para tentar impedir que sentimentos como culpa e as poucas lembranças do bebê não sejam suficientes para que ele seja eterno no seio desta família. (Ichikawa et al., 2017).

\section{Categoria II - A Enfermeira Frente à Situação de Luto Perinatal.}

Em razão da forte aproximação com o recém-nascido e seus familiares, a equipe da Unidade Terapia Intensiva Neonatal (UTIN), principalmente, a enfermagem trabalha com episódios extremamente difíceis. (Almeida, Moraes \& Cunha, 2015).

A vulnerabilidade e dor de um neonato em situação iminente de óbito, assim como a sensação de aflição e instabilidade da família são comuns no dia-a-dia da enfermeira. Destaca-se ainda, que de qualquer maneira é mais doloroso admitir o óbito de um neonato que de um homem (Almeida, Moraes \& Cunha, 2015).

Sobre o profissional expor que lidar com o óbito de um recém-nascido é mais difícil que de adultos, estudos revelam que toda morte configura um problema e exige ajuste e reestruturação, alterando o trajeto de vida comum. Para o homem é complicado se deparar com a finitude, mesmo compreendendo que é um processo natural. (Almeida, Moraes \& Cunha, 2015).

As ferramentas tecnológicas, ao dispor da equipe de saúde, acarretam uma prorrogação da evolução do óbito e, como consequência, a uma dor extra para a família deste bebê. O sentimento é de que o óbito pode ser ignorado e a equipe se sente pressionada a investir todas as forças para estender o tempo de vida do cliente. (Almeida, Moraes \& Cunha, 2015).

De acordo com Almeida, Moraes e Cunha, 2015: Os anos de trabalho no setor, vivendo regularmente estas situações, leva a enfermeira a empregar alguns comportamentos que colaboram no enfretamento desses casos. Contudo, de modo algum se apresenta preparada para a condição do falecimento do neonato, no qual, às vezes não sabe como comunicar à família.

A enfermeira compreende que os familiares precisam viver as fases de luto e não mede esforços para auxiliá-los a passar por elas com o mínimo sofrimento possível. Ofertar um local para acolher e ouvir ativamente as emoções também beneficia a família, para que eles busquem um sentindo para essa ausência. (Almeida, Moraes \& Cunha, 2015).

Tratamentos voltados para o cuidado paliativo, como auxílio e instrução de clientes e seus familiares, ajudam a minimizar os impactos emocionais e danos permanentes. Muitas unidades de saúde apresentam esquemas de cuidados paliativos perinatais e projetos de luto para auxiliar em decisões complicadas. (Ryan, Bernhard \&Fahlberg, 2015).

Independente do setor alocado, a enfermeira pode ofertar cuidado paliativo para familiares que perdem um neonato.Muitos genitores exprimem sobre sua vivência no ambiente hospitalar com desagrado por situações em que os profissionais não ofereceram o apoio adequado. (Ryan, Bernhard \&Fahlberg, 2015).

A experiência da enfermeira na UTIN não é o bastante para ajudá-la a encarar o falecimento de um bebê. Sensação de culpabilidade, frustação e recusa do óbito emergem, refletindo obstáculos para entender o processo morte-morrer nesse instante. Comunicar o óbito aos genitores do recém-nascido é outra ocasião difícil, este profissional sente dificuldade em encarar o sofrimento do próximo e lidar com ele, visto que não conhece as fraquezas e limitações desses responsáveis. (Ryan, Bernhard \& Fahlberg, 2015). 
A recusa do óbito confirma que a equipe não se mostra pronta para essa situação de partida, precisando de apoio psicológico para ofertar cuidado adequado a seus pacientes. A partir do exposto, fica clara a necessidade de atenção nos cuidados e práticas contínuas não apenas para a família, mas também para o profissional. Isso estimula a conexão entre ambos, fazendo com o que a enfermeira perceba os aspectos da família, compreendendo assim as suas fraquezas e ofertando uma assistência qualificada. (Silva \& Rocha, 2011).

Dessa forma, é necessária a orientação profissional em relação ao diálogo eficaz e empático na assistência ao neonato em processo de finitude. Operar no dia a dia da UTIN exige maturidade e capacidade metodológica. Esta capacidade precisa ser executada de forma contínua no hospital, iniciando graduação, em sequência na pós e nos procedimentos de educação em práticas sobre a assistência no fim da vida. (Ichikawa et al., 2017).

A enfermeira, além de ofertar oportunidade de recordações como o toque ou uma mecha de cabelo do natimorto aos pais, por exemplo, necessitam de capacitação para segurança e compreensão do amparo a essa condição. Pais que têm a chance de olhar e carregar neonato no colo superam o luto de forma mais compreensível, isso está ligado com menores indícios de transtorno de estresse pós-traumático. (Paris, Montigny \& Pelloso, 2016).

Nota-se o dever de propagação das vivências de equipes de trabalhadores de saúde com genitores que passaram pelo processo de perda, que conseguiram edificar hábitos de amparo, afeição e consideração ao sofrimento familiar, ao concordarem que a família enlutada conseguisse partilhar suas experiências em grupo, compreendendo o que pode ser realizado para amenizar essa dor e possivelmente evitando óbitos futuros. (Paris, Montigny \& Pelloso, 2016).

\section{Considerações Finais}

Conclui-se que a perda perinatal é uma situação extremamente delicada. É preciso compreender a assistência de maneira diferenciada, ofertada de modo humanizado, aprofundado em bases científicas e permitindo os impactos vivenciados pelos familiares, através de suas conexões com si mesmo e com os demais.

Assistir um recém-nascido que vem a óbito e sua família apresenta-se como uma condição dura para a enfermeira, que procura métodos para enfrentar a dor, através de lágrimas ou pedindo apoio para outros profissionais, no momento que se sente incapaz de assistir a família. Ela compreende o tamanho da tristeza dos familiares quanto ao óbito do bebê, e dedica-se em ampará-los nesse período difícil.

A enfermeira precisa conceder à família um espaço receptivo, oferecendo uma escuta ativa e compreendendo o silêncio dos pais. Destaca-se, também, o estabelecimento de vínculo com a família, este é fundamental. Embora, todo sofrimento e tristeza experimentada, a enfermeira expõe a sensação de compromisso completo, ao compreender que trabalhou dentro de todas as suas possibilidades na assistência ao recém-nascido e seus genitores.

Cabe informar a mulher sobre o direito que a mesma tem referente a licença maternidade que resulta no afastamento remunerado de suas atividades por 120 dias. Propiciar esse esclarecimento é de grande valia nesse momento, pois a lei garante a estabilidade no emprego.

O desenvolvimento de equipes multiprofissionais que se encontram regularmente pode ser muito eficaz, pois permite um ambiente em que os profissionais de saúde exponham suas emoções e obstáculos, reduzindo suas aflições. Outro ponto relevante é o preparo do profissional para enfrentar condições de luto e óbito desde o princípio de sua construção acadêmica.

Fica clara a necessidade de assistência dos familiares e profissionais que enfrentaram a perda perinatal. Destaca-se, ainda, a relevância de uma rede de apoio para as famílias que passaram por esse dilema, podendo até mesmo ofertar grupos de apoio pós-perda. Nessas condições, o acompanhamento não deve ser realizado apenas com mulheres mães, mas com toda família e profissionais envolvidos. 
A partir das pesquisas realizadas para a construção deste estudo, os autores notaram a necessidade de elaborar outras buscas sobre a temática e área envolvidas em questão, aprofundando-se cada vez mais. Desta maneira, acreditamos que futuramente teremos outros projetos para apresentar e assim, colaborar com a pesquisa, as comunidades acadêmicas e principalmente com a sociedade.

\section{Referências}

Almeida, F. de A., et al. (2016). Cuidando do neonato que está morrendo e sua família: vivências do enfermeiro de terapia intensiva neonatal. Revista da Escola de Enfermagem da USP, 50, 122-129. https://doi.org/10.1590/S0080-623420160000300018

Aguiar, H., \& Zorning, S. (2016) Luto fetal: a interrupção de uma promessa. PEPSIC, 21(2). http//dx.doi.org/0.11606/issn.1981-1624.v21i2p264-281

Bimbatti César, M., Nogueira, P. S., Miranda, C. M., \& Rolim, A. M. (2015). O luto da puérpera de um natimorto. IX Congresso Brasileiro de Enfermagem Obstétrica e Neonatal.

Consolidação das Leis do Trabalho (CLT). (2016)

Gold, K. Navegando na assistência após a morte de um bebê: uma revisão sistemática das experiências dos pais com os profissionais de saúde. $J$ Perinatol 27, 230-237 (2007). https://doi.org/10.1038/sj.jp.7211676

Gonçalves, P. C., \& Bittar, C. M. L. (2016). Mudanças - Psciologia da Saúde, 24(1), 39-44, 2016.

Hutti, M. H., Armstrong, D. S., Myers, J. A. H., \& Lynn A. (2015). Intensidade do luto, bem-estar psicológico e relacionamento íntimo com parceiros na gravidez subsequente após uma perda perinatal. Journal of Obstetric Gynecologi camp Neonatal Nursing. 44(1), 42-50: https://doi.org/10.1111/1552-6909.12539.

Ichikawa, C. R. de F.; Sampaio, P. S. S.; Sá, N. N.; Szylit, R.; Santos, S. S. C.; \& Vargas, D. (2017). O cuidado à família diante da perda neonatal: uma reflexão sob a ótica da teoria da complexidade.Revenferm UFPE online. Recife, 11(12):5085-91.https://doi.org/10.5205/1981-8963-v11i12a22610p5085-5091-2017

Montero, S. M. P., et al (2011). A experiência da perda perinatal a partir da perspectiva dos profissionais de saúde. Rev. Latino-Am. Enfermagem Artigo Original 19(6) www.eerp.usp.br/rlae.

Muza, J. C., et al (2013). Quando a morte visita a maternidade: atenção psicológica durante a perda perinatal. Psicologia: teoria e prática, 15(3), 34-48. Recuperado em 03 de julho de 2020, de http://pepsic.bvsalud.org/scielo.php?script=sci_arttext\&pid=S1516-36872013000300003\&lng=pt\&tlng=pt.

Paris, G. F., et al (2016). Fatores associados ao estado de luto após óbito fetal: estudo comparativo entre brasileiras e canadenses. Revista da Escola de Enfermagem da USP, 50(4), 546-553. https://doi.org/10.1590/S0080-623420160000500002

Paris, G. F., et al (2017). Adaptação Transcultural E Evidências De Validação Da Perinatal Grief Scale. Texto \& Contexto - Enfermagem, $26(1)$, e5430015. https://doi.org/10.1590/0104-07072017005430015

Pereira, A. S.; et al. (2018). Metodologia Da Pesquisa Científica. UFSM. < https://repositorio.ufsm.br/bitstream/handle/1/15824/Lic_Computacao_MetodologiaPesquisa-Cientifica.pdf?sequence $=1>$

Pereira, M. U. L., et al (2018). Comunicação Da Notícia De Morte E Suporte Ao Luto De Mulheres Que Perderam Filhos Recém-Nascidos. Revista Paulista de Pediatria, 36(4), 422-427. https://dx.doi.org/10.1590/1984-0462/;2018;36;4;00013

Rios, T. dos S., et al (2016). Elaboração do processo de luto após uma perda fetal: relato de experiência. Revista de Psicologia da IMED, 8(1): 98-107, 10.18256/2175-5027/psico-imed.v8n1p98-107

Ryan, A. et al (2019). Melhores práticas para cuidados perinatais, Enfermagem 2019. 45(10). 14-15. 10.1097 / 01.NURSE.0000471422.49754.9b.

Santos, C. S., Marques, J. F., Carvalho, F. H. C., Fernandes, A. F. C., Henriques, A. C. P. T. \& Moreira, K. A. P. (2012). Percepções de enfermeiras sobre a assistência prestada a mulheres diante do óbito fetal. Escola Anna Nery. 